\title{
Effect of Continuity of Care on Emergency Department Visits in Elderly Patients with Asthma in Taiwan
}

\author{
Yu-Hsiang Kao, PhD, and Shiao-Chi Wu, PhD
}

Background: Continuity of care (COC) is positively associated with health care outcomes. However, the effect of COC on the reduction of asthma-related emergency department (ED) visits among older asthmatic patients is not clearly understood.

Methods: We conducted a retrospective cohort study using the Taiwan nationwide health insurance claims database between 2004 and 2013. Patients aged 65 years with asthma during 2005 to 2011 were selected. The COC index (COCI) is used to measure the number of individual physicians a patient sees in the first year and we identified asthma-related ED visit in the subsequent year. Cox model was used to examine the hazard ratio (HR) between COC and an ED visit for asthma.

Results: Among a total of 3395 subjects, the overall mean COC was 0.73 , and $48.5 \%$ of subjects had perfect COC $(C O C I=1)$. After controlling for covariables, in the group of patients with low COC, the risk of having an asthma-related ED visit was higher compared with those with perfect COC (Adjusted HR, 2.11; 95\% CI, 1.37-3.25).

Conclusions: Elderly asthmatic patients with lower COC had a significantly higher likelihood of having asthma-related ED visits. (J Am Board Fam Med 2017;30:384-395.)

Keywords: Ambulatory Care, Asthma, Continuity of Care, Emergency Departments, Retrospective Studies, Taiwan

Asthma is a chronic inflammatory respiratory disease and is associated with various morbidities ${ }^{1}$ and high medical costs. ${ }^{2}$ A common misconception is that asthma occurs only in childhood. A considerable number of studies focus on children with asthma; however, few studies have examined asthma in adults. ${ }^{3}$ Asthma also occurs in people aged $>40$ years. ${ }^{4}$ The prevalence of asthma among people aged $\geq 65$ years is approximately $7 \%$ in Taiwan, ${ }^{5}$ which is similar to that in the United States. ${ }^{6,7}$ The average annual rate of outpatient visits for older patients with asthma in Taiwan is 6.3 per 100

\footnotetext{
This article was externally peer reviewed.

Submitted 12 September 2016; revised 9 January 2017; accepted 9 January 2017.

From the Institute of Health and Welfare Policy, National Yang-Ming University, Taipei, Taiwan.

Funding: This study was supported by grants from the Ministry of Science and Technology (103-2410-H-010011-MY2 and 105-2410-H-010-011-MY2) in Taiwan.

Conflict of interest: none declared.

Corresponding author: Shiao-Chi $\mathrm{Wu}, \mathrm{PhD}$, Institute of Health and Welfare Policy, National Yang-Ming University, No. 155 Li-Nong St. Sec 2, Peitou, Taipei, Taiwan (E-mail: scwu@ym.edu.tw).
}

persons ${ }^{8}$ and this rate is also similar to that in the United States (5.6 per 100 persons). ${ }^{7}$ The mortality rate among older people with asthma is higher than that among adults or children with asthma. ${ }^{7,9,10}$ In addition, health care utilization is higher among older people with asthma than their healthy peers. ${ }^{11}$ Therefore, an investigation of elderly patients with asthma is necessary because of societal aging.

The Global Initiative for Asthma has indicated that the symptoms and frequency of exacerbations can be controlled and patients' quality of life improved if patients receive regular and continuous medication and appropriate disease management. ${ }^{12}$ To ensure that health care providers are aware of the treatment goals of providing better care for patients with asthma, ${ }^{13}$ Taiwan's government published the Taiwan Asthma Guidelines in 2000, following the Global Initiative for Asthma guidelines.

Poor asthma management on the part of health care providers and patients often increases asthmarelated health care utilization and expenditures. ${ }^{14}$ Hence, asthma is an ambulatory care-sensitive condition (ACSC). ${ }^{15}$ ACSCs are conditions character- 
ized by episodes that may have been avoided if the condition had been more effectively managed. ${ }^{16-18}$ According to the concept of ACSC, asthma is classified as a condition that is urgent but treatable with primary care during emergency department (ED) visits. ${ }^{19,20}$ Continuity of care (COC) is a process in which a patient and a medical team are cooperatively involved in ongoing health care management. Although studies have linked high COC to less hospitalization, ${ }^{21,22}$ the relationship between COC and ED visits among aging adults remains unclear. Studies have ascribed better health care outcomes in chronic diseases, such as asthma, to high COC. ${ }^{23-26}$ However, the effect of COC on aging populations with asthma has not yet been well explored.

Taiwan implemented a single-payer National Health Insurance (NHI) program in 1995, and approximately $99 \%$ of Taiwan's 23 million residents are enrolled in this program. The NHI program provides universal and compulsory health insurance to reduce financial barriers and strengthen the accessibility of health services. ${ }^{27}$ Furthermore, $70 \%$ of primary care is provided in clinics, and $30 \%$ of outpatient care is provided in hospitals. Under the NHI program, patients can freely visit any health care provider in a clinic or in a hospital, without a referral. This study investigated whether high continuity of ambulatory asthma care reduces asthmarelated ED visits among the aging population with asthma under a national insurance system without referral arrangements.

\section{Methods}

\section{Study Data and Design}

A population-based, retrospective cohort study was conducted using the 2004 to 2013 NHI Research Database and was organized by the National Health Research Institutes. This study used the Longitudinal Health Insurance Database 2010, which contains data from 1 million beneficiaries randomly selected from all insured beneficiaries in 2010 and covers approximately 1/23 of the NHI enrollee population. This data set contains all administration claims data for these beneficiaries for the period from 2004 to $2013 .{ }^{8}$ To protect patients' privacy, identifying information is encrypted and can be linked by an encrypted but unique number. These data files also provide longitudinal medical records and the International Classification of Dis- eases, Ninth Revision, Clinical Modification (ICD9-CM) codes of each patient. The accuracy of the data and diagnoses retrieved from the database has been validated. ${ }^{28}$ This study protocol was reviewed and approved by the Institutional Review Board of National Yang-Ming University, Taiwan (approval no. YM103047E).

\section{Study Population}

The study population comprised patients aged $\geq 65$ years who either had at least 2 ambulatory visits or had 1 inpatient visit for asthma ${ }^{29}$ as a major diagnosis (ICD-9-CM code 493.xx) during the period from 2005 to $2011(\mathrm{n}=8173)$. Patients who were not continuously enrolled in the NHI program $(\mathrm{n}=326)$ or had no outpatient visits $(\mathrm{n}=269)$ during the study period were excluded. Furthermore, patients with $<4$ outpatient visits during the COC period were excluded $(\mathrm{n}=4183) .{ }^{25,26,30,31} \mathrm{In}$ total, 3395 patients were included (Figure 1).

The index date was set as the earliest date for patients who had $>1$ record during this period. To avoid time-dependent bias and incorrect conclusions, we examined COC and health outcomes independently, and each patient was followed for 2 years after the index date. The first year was the COC period, and the subsequent year was the outcome period (Figure 2).

\section{Variables}

\section{Dependent Variable}

According to the prevention quality indicator of the US Agency for Healthcare Research and Quality, $\mathrm{ED}$ visits for asthma were identified by the main ICD-9-CM diagnostic code 493.xx. ${ }^{32}$ An ED visit was defined as an event that occurred during the outcome period. The follow-up duration was defined as the number of days from the date of the end of the COC period to the date of an ED visit for asthma. If a patient had no ED visit for asthma, then that patient was censored at the end of the outcome period.

\section{Independent Variable}

The score of the continuity of care index (COCI), ranging from 0 to 1 , reflects the dispersion of contact between a patient and a physician. ${ }^{33} \mathrm{~A}$ higher value represents better COC. A COCI of 1 indicates that all outpatient visits were to the same physician; in other words, patients had a continuous connection with 1 physician. This index has 
Figure 1. Diagrammatic representation of the patient populations. *The results of analysis among those patients are demonstrated in Appendix Table 1. Coc, continuity of care.

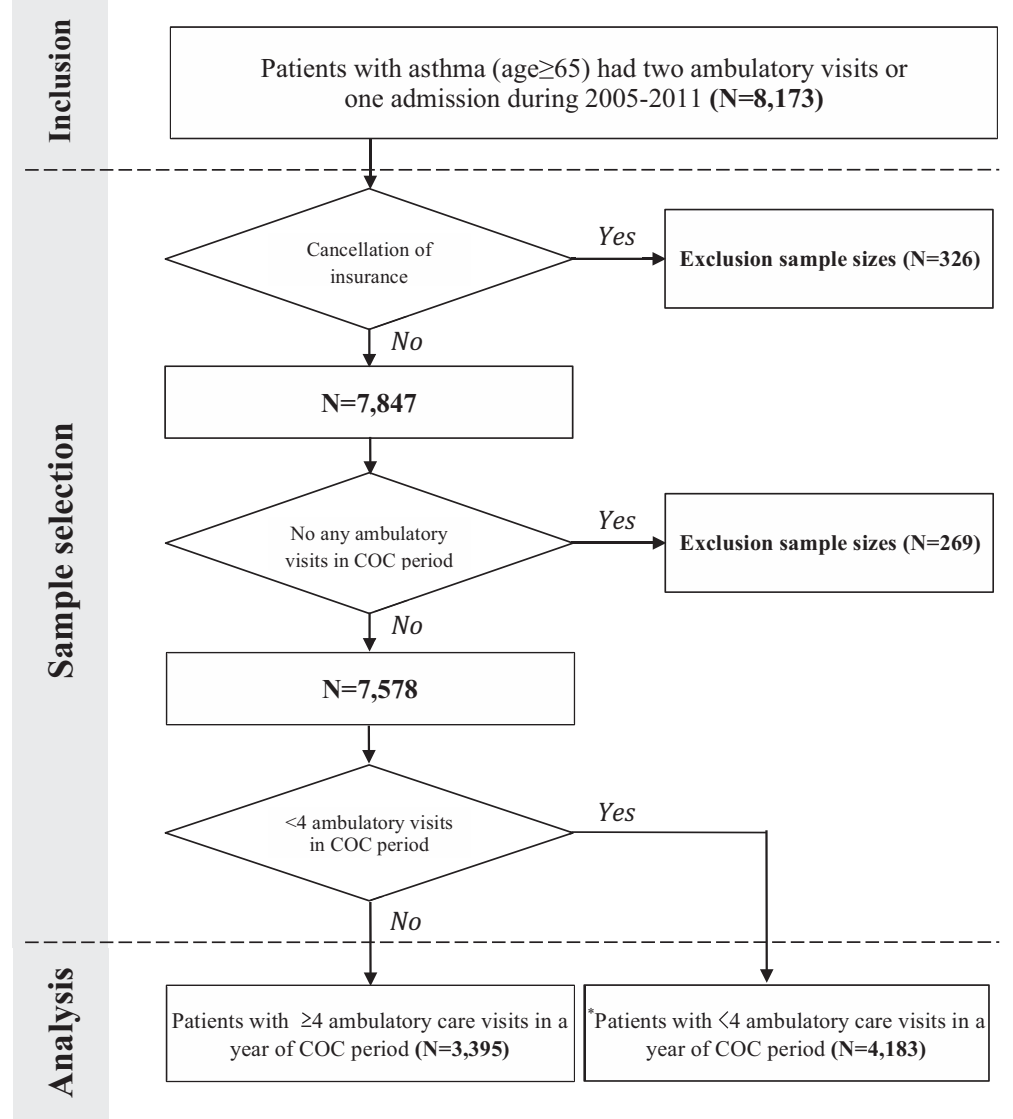

been widely adopted in studies using claim data sets $^{30,31,34,35}$ because the index is less sensitive to the number of physician visits and more suitable for a higher number of outpatient visits. ${ }^{33}$ The general formula for COCI is as follows:

$$
\text { COCI }=\frac{\sum_{i=1}^{j} \mathrm{n}_{i}^{2}-\mathrm{N}}{\mathrm{N}(\mathrm{N}-1)}
$$

where $N$ is the total number of outpatient asthma care visits, $n_{i}$ is the number of outpatient asthma care visits to $i$ th physician, and $j$ is the total number of physicians. The total number of physician visits $(N)$ and the number of visits to a given physician $\left(n_{i}\right)$ include ambulatory claims (including clinic or hospital physician visits) in the principal diagnosis (ICD-9-CM code 493.xx). We calculated COCI

Figure 2. The schematic diagram of the time frame. CCI, Charlson comorbidity index; COC, continuity of care; COCI, continuity of care index; COPD, chronic obstructive pulmonary disease; ED, emergency department.

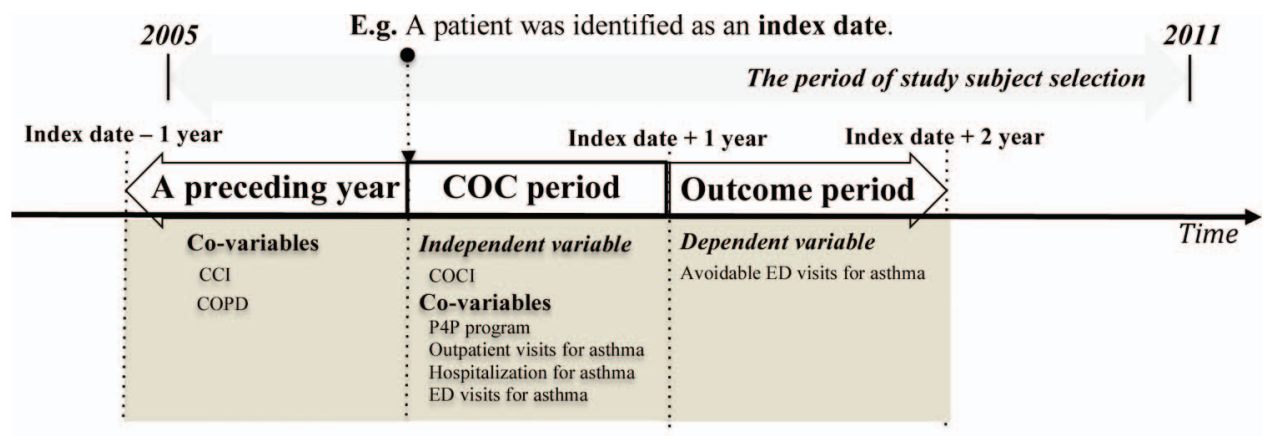


during the COC period and then categorized COCI into 3 groups according to the first and third quartiles: low (COCI $<0.47)$, moderate $(0.47 \leq$ COCI $<1)$, and perfect $(\mathrm{COCI}=1){ }^{36}$

\section{Covariables}

Several covariables were considered in this study. Patient characteristics at baseline were age, sex, and insurance premiums (low [ $<$ US\$667], medium [US\$667-1333], and high [ $\geq$ US\$1333]). One US dollar was equal to $30 \mathrm{New}$ Taiwan dollars in 2012. ${ }^{37}$ Patients' educational level or household income may affect health care outcomes ${ }^{6,23,38}$; the NHI claims data set does not provide this information. Hence, insurance premiums were used as a proxy for socioeconomic status. ${ }^{39}$ Enrollment in the asthma pay-for-performance $(\mathrm{P} 4 \mathrm{P})$ program during the COC period was considered because the $\mathrm{P} 4 \mathrm{P}$ program has been proven to improve both COC and health care outcomes among patients with chronic diseases. ${ }^{35,40-42}$ In addition, health status and disease severity may affect the measurement of health outcomes; therefore, we considered medical conditions in the previous year and in the COC period to identify patients' health status and disease severity. Furthermore, the Charlson Comorbidity Index (CCI) and a history of chronic obstructive pulmonary disease (COPD; ICD9-CM codes 491, 492, or 496) 22 $^{22}$ were included and identified in the previous year. The CCI, which was calculated for each patient according to outpatient or inpatient care, was divided into 3 groups: 0,1 to 2 , and $\geq 3 .{ }^{43}$ The number of ambulatory visits for asthma (4-12, 13-24, and $\geq 25$ times), ${ }^{25,26,30}$ whether a patient was hospitalized for asthma, ${ }^{24}$ and whether a patient had an ED visit for asthma ${ }^{22,24,25}$-all during the COC period-were used as proxies for disease severity.

\section{Statistical Analysis}

The association of patients' characteristics with COC was examined using the $\chi^{2}$ test for categorical variables and 1-way analysis of variance for continuous variables. The Cochran-Armitage trend test was used to evaluate the association of asthmarelated ED visits with the level of COC. In addition, with the valid proportional hazard assumption $(P=.927),{ }^{44}$ Cox regression models were used to examine the association between COC levels and the risk of $\mathrm{ED}$ visit for asthma in elderly patients with asthma. In the adjusted model, we calculated the adjusted hazard ratio (aHR) after adjusting for sex, age, insurance premium, $\mathrm{P} 4 \mathrm{P}$ participation status, CCI, COPD, number of ambulatory visits for asthma, hospitalization for asthma, and ED visits for asthma. All variables had no multicollinearity in our model. In addition to these models, we conducted a supplementary analysis including patients with $<4$ annual visits.

All analyses were performed using SAS version 9.4 (SAS Institute, Cary, NC). All tests were 2 -sided, and a $P$ value $<.05$ was defined as statistically significant for all tests.

\section{Results}

Table 1 lists the characteristics of the patients with asthma $(\mathrm{n}=3395)$. The average COCI of elderly patients with asthma was 0.73 (standard deviation $=0.3$; data not shown). Furthermore, 1663 (49.0\%), 906 (26.7\%), and $826(24.3 \%)$ patients were included in the perfect $(\mathrm{COCI}=1)$, moderate $(\mathrm{COCI}=0.47-0.99)$, and low $(\mathrm{COCI}<0.47)$ COC groups, respectively. Across the entire sample, the mean age was 74.0 years and men comprised $50.5 \%$ of the patients. Furthermore, $56.3 \%$ of the patients had a low insurance premium, and $89.7 \%$ of the patients did not participate in the asthma $\mathrm{P} 4 \mathrm{P}$ program. Regarding medical conditions during the COC period, $80.5 \%$ of the patients had 4 to 12 ambulatory visits. The proportion of patients with a history of COPD $(77.7 \%)$, the number of asthma-related outpatient visits (83.8\%), and the number of asthma-related hospitalizations (98.5\%) and ED visits (96.8\%) during the COC period were lower in the perfect COC group than in the low and moderate COC groups.

The incidence of asthma-related ED visits is shown in Table 2. The overall rate was $3.45 \%$, and it increased significantly with a decrease in the level of COCI (perfect: $2.22 \%$, moderate: $3.31 \%$, and low: $6.05 \%$; $P$ for trend <.01). Of the patients' characteristics at baseline, a significant dose-response association was identified for sex, a low insurance premium, and no participation in the asthma $\mathrm{P} 4 \mathrm{P}$ program $(P$ for trend $<.01)$. An increased rate of $\mathrm{ED}$ visits was found to correlate with a decreased level of COC among the patients with a CCI of $\geq 3$ and patients with a history of COPD ( $P$ for trend <.01). The incidence of asthmarelated ED visits across the 3 COCI levels tended to increase significantly among the patients with 4 to 12 
Table 1. Characteristics of Subjects $(\mathrm{N}=3395)$ by Continuity of Care Index Group

\begin{tabular}{|c|c|c|c|c|c|}
\hline \multirow[b]{2}{*}{ Characteristics } & \multirow[b]{2}{*}{ Subjects } & \multicolumn{3}{|c|}{ Level of COCI (\%) } & \multirow[b]{2}{*}{$P$ Value* } \\
\hline & & $<0.47(\mathrm{n}=826)$ & $0.47-0.99(\mathrm{n}=906)$ & $1(\mathrm{n}=1663)$ & \\
\hline Total & 100.0 & 24.3 & 26.7 & 49.0 & \\
\hline \multicolumn{6}{|l|}{ Patient characteristics at baseline } \\
\hline Sex & & & & & .111 \\
\hline Female & 49.5 & 49.9 & 52.1 & 47.8 & \\
\hline Male & 50.5 & 50.1 & 47.9 & 52.2 & \\
\hline Age, years $($ mean $\pm \mathrm{SD})$ & $74.0(6.2)$ & $73.7(6.2)$ & $74.0(6.0)$ & $74.2(6.2)$ & .155 \\
\hline Insurance premium (US\$) & & & & & .147 \\
\hline$<667$ & 56.3 & 56.8 & 57.5 & 55.4 & \\
\hline $667-1333$ & 27.1 & 26.3 & 24.5 & 28.9 & \\
\hline$>1333$ & 16.6 & 17.0 & 18.0 & 15.7 & \\
\hline $\mathrm{P} 4 \mathrm{P}$ participating status & & & & & .867 \\
\hline Not a participant & 89.7 & 90.1 & 89.3 & 89.7 & \\
\hline Participant & 10.3 & 9.9 & 10.7 & 10.3 & \\
\hline \multicolumn{6}{|l|}{ Medical conditions } \\
\hline \multicolumn{6}{|l|}{ In a preceding year } \\
\hline CCI & & & & & .094 \\
\hline 0 & 17.0 & 17.1 & 14.4 & 18.3 & \\
\hline $1-2$ & 11.9 & 12.8 & 12.4 & 11.1 & \\
\hline$\geq 3$ & 71.1 & 70.1 & 73.3 & 70.5 & \\
\hline COPD & & & & & .004 \\
\hline No & 75.3 & 72.0 & 73.7 & 77.7 & \\
\hline Yes & 24.7 & 28.0 & 26.3 & 22.3 & \\
\hline \multicolumn{6}{|l|}{ In the COC period } \\
\hline Ambulatory visits for asthma, $\mathrm{n}$ & & & & & $<.001$ \\
\hline $4-12$ & 80.5 & 82.7 & 72.6 & 83.8 & \\
\hline $13-24$ & 17.3 & 14.9 & 24.1 & 14.9 & \\
\hline$\geq 25$ & 2.2 & 2.4 & 3.3 & 1.4 & \\
\hline Hospitalization for asthma & & & & & $<.001$ \\
\hline No & 97.0 & 95.4 & 95.6 & 98.5 & \\
\hline Yes & 3.0 & 4.6 & 4.4 & 1.5 & \\
\hline ED visits for asthma & & & & & $<.001$ \\
\hline No & 94.5 & 91.0 & 93.5 & 96.8 & \\
\hline Yes & 5.5 & 9.0 & 6.5 & 3.2 & \\
\hline \multicolumn{6}{|l|}{ Healthcare outcome } \\
\hline ED visits for asthma & & & & & $<.001$ \\
\hline No & 96.5 & 93.9 & 96.7 & 97.8 & \\
\hline Yes & 3.5 & 6.1 & 3.3 & 2.2 & \\
\hline
\end{tabular}

Data are percentages unless otherwise indicate.

${ }^{*} \chi^{2}$ test for difference in the level of Continuity of Care Index (COCI).

CCI, Charlson comorbidity index; COPD, chronic obstructive pulmonary disease; ED, emergency department; P4P, pay for performance; SD, standard deviation.

or 13 to 24 ambulatory visits, those not requiring hospitalization, and those having ED visits during the COC period ( $P$ for trend $<.01$ ).

The risk of ED visits for asthma is demonstrated in Table 3. The patients in the low COC group had a significantly higher risk of asthma-related ED visits than did the patients in the perfect COC group (aHR, 2.11; 95\% confidence interval [CI], 1.37-3.25). However, the patients in the moderate COC group exhibited a tendency to visit the ED because of asthma (aHR, 1.15; 95\% CI, 0.70-1.87). Furthermore, patients with COPD were more likely to have asthma-related ED visits (aHR, 2.20; 95\% CI, 1.46-3.30). Compared with the patients 
Table 2. Incidence of Emergency Department Visits Across Continuity of Care Index Groups $(\mathbf{n}=3395)$

\begin{tabular}{|c|c|c|c|c|c|}
\hline \multirow[b]{2}{*}{ Variables } & \multirow[b]{2}{*}{ Total $(\mathrm{n}=3395)$} & \multicolumn{3}{|c|}{ Level of COCI } & \multirow[b]{2}{*}{$P$ for trend ${ }^{*}$} \\
\hline & & $<0.47(\mathrm{n}=826)$ & $0.47-0.99(\mathrm{n}=906)$ & $1(\mathrm{n}=1663)$ & \\
\hline Overall & 3.45 & 6.05 & 3.31 & 2.22 & $<.01$ \\
\hline \multicolumn{6}{|c|}{ Patient characteristics at baseline } \\
\hline \multicolumn{6}{|c|}{ Sex } \\
\hline Female & 1.33 & 2.18 & 1.43 & 0.84 & $<.01$ \\
\hline Male & 2.12 & 3.87 & 1.88 & 1.38 & $<.01$ \\
\hline \multicolumn{6}{|c|}{ Insurance premiums (US\$) } \\
\hline$<667$ & 2.06 & 3.75 & 2.21 & 1.14 & $<.01$ \\
\hline $667-1333$ & 0.97 & 1.57 & 0.77 & 0.78 & .09 \\
\hline$\geq 1333$ & 0.41 & 0.73 & 0.33 & 0.30 & .19 \\
\hline \multicolumn{6}{|c|}{$\mathrm{P} 4 \mathrm{P}$ participating status } \\
\hline Not a participant & 3.15 & 5.45 & 3.09 & 2.04 & $<.01$ \\
\hline Participant & 0.29 & 0.61 & 0.22 & 0.18 & .12 \\
\hline \multicolumn{6}{|l|}{ Medical conditions } \\
\hline \multicolumn{6}{|l|}{ In a preceding year } \\
\hline \multicolumn{6}{|l|}{ CCI } \\
\hline 0 & 0.38 & 0.61 & 0.22 & 0.36 & .50 \\
\hline $1-2$ & 0.12 & 0.12 & 0.22 & 0.06 & .78 \\
\hline$\geq 3$ & 2.95 & 5.33 & 2.87 & 1.80 & $<.01$ \\
\hline \multicolumn{6}{|l|}{ COPD } \\
\hline No & 1.77 & 2.78 & 1.99 & 1.14 & $<.01$ \\
\hline Yes & 1.68 & 3.27 & 1.32 & 1.08 & $<.01$ \\
\hline \multicolumn{6}{|l|}{ In the COC period } \\
\hline \multicolumn{6}{|c|}{ Ambulatory visits for asthma, $\mathrm{n}$} \\
\hline $4-12$ & 2.09 & 3.51 & 1.77 & 1.56 & $<.01$ \\
\hline $13-24$ & 1.12 & 2.06 & 1.32 & 0.54 & $<.01$ \\
\hline$\geq 25$ & 0.24 & 0.48 & 0.22 & 0.12 & .13 \\
\hline \multicolumn{6}{|c|}{ Hospitalization for asthma } \\
\hline No & 3.15 & 5.33 & 3.31 & 1.98 & $<.01$ \\
\hline Yes & 0.29 & 0.73 & 0.00 & 0.24 & .12 \\
\hline \multicolumn{6}{|c|}{ ED visits for asthma } \\
\hline No & 2.36 & 3.63 & 2.43 & 1.68 & $<.01$ \\
\hline Yes & 1.09 & 2.42 & 0.88 & 0.54 & $<.01$ \\
\hline
\end{tabular}

*Cochran-Armitage trend test.

CCI, Charlson Comorbidity Index; COCI, continuity of care index; COPD, chronic obstructive pulmonary disease; ED, emergency department; $\mathrm{P} 4 \mathrm{P}$, pay for performance.

having 4 to 12 ambulatory visits, the patients having 13 to 24 or $\geq 25$ ambulatory visits during the COC period were $124 \%$ (aHR, 2.24; 95\% CI, $1.49-3.36$ ) or $203 \%$ (aHR, 3.03; 95\% CI, $1.44-$ 6.39) more likely to have more ED visits for asthma, respectively. Moreover, experience of asthma-related ED visits during the COC period was associated with a higher risk of asthma-related ED visits (aHR, 6.69; 95\% CI, 4.40-10.17). No significant interactions were observed between the COC groups and other variables in the regression model. The results of the supplementary analysis including the patients with $<4$ annual visits were consistent with those obtained from the original models (Appendix Table 1).

\section{Discussion}

Taiwanese nationwide claims data were used in this study to examine the association between COC and asthma-related ED visits among older patients with asthma. The results of this study revealed that half of the elderly patients with asthma in Taiwan received ambulatory asthma care from a single physician during the first observational year, and the average COCI was 0.73 among the study popula- 
Table 3. Factors Associated with Emergency Department Visits for Asthma Using Cox Models $(\mathrm{n}=3395)$

\begin{tabular}{|c|c|c|c|c|}
\hline \multirow[b]{2}{*}{ Variables } & \multicolumn{2}{|c|}{ Crude Model } & \multicolumn{2}{|c|}{ Adjusted model } \\
\hline & HR & $95 \% \mathrm{CI}$ & HR & $95 \% \mathrm{CI}$ \\
\hline \multicolumn{5}{|l|}{ COCI } \\
\hline 1 (Reference) & 1.00 & & 1.00 & \\
\hline $0.47-0.99$ & 1.50 & $0.92-2.42$ & 1.15 & $0.70-1.87$ \\
\hline$<0.47$ & 2.78 & $1.81-4.25$ & 2.11 & $1.37-3.25$ \\
\hline \multicolumn{5}{|l|}{ Patient characteristics at baseline } \\
\hline \multicolumn{5}{|l|}{ Sex } \\
\hline Female (reference) & 1.00 & & 1.00 & \\
\hline Male & 1.58 & $1.09-2.30$ & 1.29 & $0.88-1.90$ \\
\hline Age (years) & 1.00 & $0.97-1.03$ & 0.98 & $0.95-1.01$ \\
\hline \multicolumn{5}{|l|}{ Insurance premium (US\$) } \\
\hline$<667$ (Reference) & 1.00 & & 1.00 & \\
\hline $667-1333$ & 0.98 & $0.65-1.48$ & 1.13 & $0.74-1.72$ \\
\hline$\geq 1333$ & 0.67 & $0.38-1.19$ & 0.94 & $0.52-1.69$ \\
\hline \multicolumn{5}{|l|}{$\mathrm{P} 4 \mathrm{P}$ participating status } \\
\hline Not participating (reference) & 1.00 & & 1.00 & \\
\hline Participating & 0.81 & $0.42-1.55$ & 0.78 & $0.40-1.50$ \\
\hline \multicolumn{5}{|l|}{ Medical conditions } \\
\hline \multicolumn{5}{|l|}{ In a previous year } \\
\hline \multicolumn{5}{|l|}{ CCI } \\
\hline 0 (Reference) & 1.00 & & 1.00 & \\
\hline $1-2$ & 0.44 & $0.14-1.34$ & 0.37 & $0.12-1.15$ \\
\hline$\geq 3$ & 1.85 & $1.04-3.29$ & 1.00 & $0.53-1.87$ \\
\hline \multicolumn{5}{|l|}{ COPD } \\
\hline \multicolumn{5}{|l|}{ No (reference) } \\
\hline Yes & 2.97 & $2.07-4.27$ & 2.20 & $1.46-3.30$ \\
\hline \multicolumn{5}{|l|}{ In the COC period } \\
\hline \multicolumn{5}{|l|}{ Ambulatory visits for asthma, $\mathrm{n}$} \\
\hline 4-12 (Reference) & 1.00 & & 1.00 & \\
\hline $13-24$ & 2.55 & $1.72-3.78$ & 2.24 & $1.49-3.36$ \\
\hline$\geq 25$ & 4.40 & $2.12-9.15$ & 3.03 & $1.44-6.39$ \\
\hline \multicolumn{5}{|l|}{ Hospitalization for asthma } \\
\hline No (reference) & 1.00 & & 1.00 & \\
\hline Yes & 3.08 & $1.61-5.89$ & 1.00 & $0.50-1.99$ \\
\hline \multicolumn{5}{|l|}{ ED visits for asthma } \\
\hline No (reference) & 1.00 & & 1.00 & \\
\hline Yes & 8.89 & $6.02-13.13$ & 6.69 & $4.40-10.17$ \\
\hline
\end{tabular}

CCI, Charlson Comorbidity Index; CI, confidence interval; COCI, continuity of care index; COPD, chronic obstructive pulmonary disease; ED, emergency department; HR, hazard ratio; P4P, pay for performance.

tion. We also observed that internists and family physicians were the principal outpatient care providers for patients in our study population; only $9 \%$ of the health care providers for our subjects were pulmonologists. A high COC score for the elderly patients with asthma might be attributable to the asthma P4P program. The Taiwan government launched the asthma P4P program in 2001 to encourage clinics and hospitals to provide patientcentered care and focus on disease management.
This program provides a financial incentive to health care providers if their patients have a high follow-up rate and a low rate of hospitalization and ED visits for asthma. In addition, a previous study reported that children with asthma in Taiwan have a higher average COC score ${ }^{41}$ than do those in America and Canada. ${ }^{24,30}$

The continuous treatment of patients with asthma through inhaled medicine provides safe and effective long-term disease management. ${ }^{45}$ Studies 
have suggested an association of superior COC with fewer ED visits in different populations with asthma. ${ }^{23,26,30,41,46}$ Our findings are consistent with those reported in a previous study focusing on children. ${ }^{41}$ That study indicated that $42.3 \%$ of children with asthma had high COC $(\mathrm{COCI}=1)$, and those with medium or low COC had a higher risk of asthma-related ED visits (odds ratio, 1.21 and 1.38 , respectively). In addition, a study investigating the effects of COC on older patients in South Korea $^{25}$ supported our finding of an inverse association between COC and the risk of asthma-related $\mathrm{ED}$ visits in elderly patients with asthma. In that study, the COCI was determined using medical institution units. Moreover, the study suggested that improved COC is associated with a lower risk of ED visits in elderly patients with asthma. Although the effect of COC may vary between different populations, our findings support the association of low COC with a high risk of ED visits for asthma in elderly populations with asthma.

The data suggest that COC plays a much more crucial role for older patients with asthma who have a low insurance premium, have providers who do not participate in the $\mathrm{P} 4 \mathrm{P}$ program, and have a high CCI score $(\mathrm{CCI} \geq 3)$. In studies focusing on adults or older people, low-income status was found to be adversely associated with health outcomes. ${ }^{22,23}$ Despite the insignificance of enrollment in the P4P program, the program seemed to be one of the factors reducing the risk of asthma-related ED visits in older patients with asthma (aHR, 0.78). A study reported that $\mathrm{P} 4 \mathrm{P}$ programs benefit patients with diabetes and improve COC as well as health outcomes. ${ }^{35}$ In addition, a randomized clinical study demonstrated that offering financial incentives to both physicians and patients can lead to superior care outcomes for patients. ${ }^{47}$ Therefore, we suggest that governments should consider designing financial incentives for patients and physicians in order to increase their motivation, thereby improving patients' COC. Furthermore, elderly patients with asthma with higher levels of comorbidity might have poor health status. Upon suffering an asthma attack, older patients with asthma should contact the physician who is their main health care provider. As a result, these patients may benefit from improving their own COC.

Older patients with asthma and COPD should be more diligent regarding follow-up care. The results of this study revealed that these patients might have an approximately 2 times higher risk of asthma-related ED visits, even after considering COC and other covariables. An increased trend in the rates of asthma-related $\mathrm{ED}$ visits was observed to correlate with decreased COC levels in these patients $(P$ for trend $<.01)$. An inverse association was reported between COC and health outcomes, such as hospitalization and ED visits, among patients with COPD. ${ }^{22,25}$ In addition, asthma-COPD overlap syndrome has been increasingly discussed recently because of the similar clinical features of asthma and COPD. ${ }^{48}$ Therefore, our results support the theory that older patients with asthma and COPD have a higher risk of ED visits. Thus, future studies should further investigate this issue to gather more evidence.

Studies evaluating COC for all diseases have reported that patients with superior COC had a lower risk of ED visits and avoidable hospitalizations. $^{23,49}$ However, the effect of COC on health outcomes can be confounded if a study includes several diseases. ${ }^{26}$ Therefore, focusing on a single disease can clarify the association between COC and health outcomes. For instance, Lin et $\mathrm{al}^{22}$ indicated that high COC was associated with a low risk of avoidable COPD-related hospitalization among adults with COPD. Our study focused on elderly patients with asthma and found a significantly inverse relationship between COC levels and the risk of ED visits for asthma. Thus, we suggest that these patients with low COC should attempt to develop a continuing relationship with a single physician in order to reduce the risk of ED visits for asthma. Our study demonstrates that COC plays a vital role in the reduction of $\mathrm{ED}$ visits for asthma among elderly patients with asthma. The findings also suggest that improving COC can be favorable for both patients and the health care system. ${ }^{36}$

This study has some limitations. First, it excluded patients with $<4$ outpatient visits during the COC period, which might limit the generalizability for these patients. ${ }^{50}$ Second, the claims data did not include the results of clinical data, such as peak expiratory flow or forced expiratory volume, to define disease severity and health status. ${ }^{38,51}$ Therefore, we referred to previous studies to adopt the frequency of ambulatory visits for asthma, ${ }^{25,26,30}$ hospitalization, ${ }^{24}$ and $\mathrm{ED}$ visits ${ }^{22,24,25}$ as a proxy for asthma severity, and we used CCI as a proxy indicator to present each patient's health status. ${ }^{21,22,52}$ Third, we could not obtain patients' educational level or household 
income, and this may affect the measurement of COC and outcomes. ${ }^{23}$ Hence, we used insurance premiums as an indicator to represent patients' socioeconomic status. ${ }^{39}$ In addition, despite measuring COC before health care outcomes, as suggested by a previous study, ${ }^{53}$ the problem of temporal ambiguity between COC and health care outcomes might not be completely avoided. We recommend that this issue should be further investigated in the future.

This study has several advantages. First, 99\% of Taiwanese residents are enrolled in the NHI program; therefore, the findings are highly representative of the entire population. Second, the nationwide administrative databases include all information on clinical practices and reduce the effect of recall bias, thereby delivering results that are superior to those from hospital-based data sets ${ }^{54}$ or national surveys. ${ }^{55}$ Third, this study applied a longitudinal design in order to avoid the problem of a crosssectional design and present stronger evidence of an association between COC and ED visits for asthma. Fourth, previous studies have explored the effect of COC on health care outcomes in children and adolescents with asthma. ${ }^{24,30,41}$ Our study provided empirical evidence of an adverse association between $\mathrm{COC}$ and the risk of ED visits among older patients with asthma. Fifth, we focused on a specific disease (asthma) and used critical criteria to identify patients; these criteria could be used more precisely to reflect the actual asthma care received and examine the association between COC and asthma-related ED visits. Previous research has reported that using a specific disease to calculate the COCI is more helpful for interpreting the relationship between COC and health outcomes. ${ }^{41,56} \mathrm{Fi}$ nally, we measured the COCI at the physician level, which may provide information about the association between COC and asthma-related ED visits among elderly patients with asthma that is superior to that obtained from measurements at the institutional level.

\section{Conclusions}

This study demonstrates that an adverse association exists between COC and the risk of ED visits among elderly asthmatics, and that a long-term continuous relationship with the same physician is favorable for elderly patients with asthma in order to improve health care outcomes. We recommend that policymakers create effective policies for elderly patients with asthma to enhance the ongoing physician-patient relationship and improve disease control.

To see this article online, please go to: http://jabfm.org/content/ 30/3/384.full.

\section{References}

1. Boulet LP, Boulay MÈ. Asthma-related comorbidities. Expert Rev Respir Med 2011;5:377-93.

2. Weiss KB, Gergen PJ, Hodgson TA. An economic evaluation of asthma in the United States. N Engl J Med 1992;326:862-6.

3. Anandan C, Nurmatov U, Van Schayck OCP, Sheikh A. Is the prevalence of asthma declining? Systematic review of epidemiological studies. Allergy 2010;65:152-67.

4. Burrows B, Barbee RA, Cline MG, Knudson RJ, Lebowitz MD. Characteristics of asthma among elderly adults in a sample of the general population. Chest 1991;100:935-42.

5. Statistics of Medical Care, National Health Insurance 2014. Available from: http://www.mohw.gov. tw/MOHW_Upload/doc/2014Medical_Care.pdf. Accessed December 5, 2017.

6. Akinbami OJ, Moorman JE, Liu X. Asthma prevalence, health care use, and mortality: United States, 2005-2009. Washington, DC : US Department of Health and Human Services, Centers for Disease Control and Prevention, National Center for Health Statistics; 2011.

7. Moorman JE, Rudd RA, Johnson CA, et al. National surveillance for asthma-United States, 1980-2004. MMWR Surveill Summ 2007;56:1-54.

8. National Health Insurance Administration. National Health Insurance annual report 2014-2015. Taipei, Taiwan: Ministry of Health and Welfare; 2014.

9. Hsiao HJ, Wang LC, Yang YH, et al. A nationwide survey of the severity, comorbidity, and mortality of hospitalized patients with asthma in Taiwan. Pediatr Neonatol 2013;54:254-60.

10. Moorman JE, Moorman J, Mannino DM. Increasing US asthma mortality rates: who is really dying? J Asthma 2001;38:65-71.

11. Smith AM, Villareal M, Bernstein DI, Swikert DJ. Asthma in the elderly: risk factors and impact on physical function. Ann Allergy Asthma Immunol 2012;108:305-10.

12. Global Initiative for Asthma. Global Strategy for Asthma Management and Prevention 2016. Availablefrom:http://ginasthma.org/wp-content/uploads/ 2016/04/GINA-2016-main-report_tracked.pdf. Accessed December 18, 2016.

13. Kuo WY, Li CC, Chen SH. Survey of the clinical practice of physicians in the management of asthma 
in Taiwan. Asian Pac J Allergy Immunol 2006;24: 1-8.

14. Coffey RM, Ho K, Adamson DM, Matthews TL, Sewell J, Kassed CA. Asthma care quality improvement: a resource guide for state action. 2009. Available from: https://www.ahrq.gov/sites/default/files/ publications/files/asthqguide.pdf. Accessed July 23, 2016.

15. National healthcare quality report, 2013. Rockville, MD: Agency for Healthcare Research and Quality; 2014.

16. Billings J, Anderson GM, Newman LS. Recent findings on preventable hospitalizations. Health Aff (Millwood) 1996;15:239-49.

17. Billings J, Zeitel L, Lukomnik J, Carey TS, Blank AE, Newman L. Impact of socioeconomic status on hospital use in New York City. Health Aff (Millwood) $1993 ; 12: 162-73$.

18. Bindman AB, Grumbach K, Osmond D, et al. Preventable hospitalizations and access to health care. JAMA 1995;274:305-11.

19. Billings J, Parikh N, Mijanovich T. Emergency room use: the New York story. Issue brief (Commonwealth Fund) 2000;434:1-12.

20. Tang N, Stein J, Hsia RY, Maselli JH, Gonzales R. Trends and characteristics of US emergency department visits, 1997-2007. JAMA 2010;304:664-70.

21. Cheng S, Chen C, Hou Y. A longitudinal examination of continuity of care and avoidable hospitalization: evidence from a universal coverage health care system. Arch Intern Med 2010;170:1671-7.

22. Lin IP, Wu SC, Huang ST. Continuity of care and avoidable hospitalizations for chronic obstructive pulmonary disease. J Am Board Fam Med 2015;28: 222-30.

23. Cree M, Bell N, Johnson D, Carriere K. Increased continuity of care associated with decreased hospital care and emergency department visits for patients with asthma. Dis Manag 2006;9:63-71.

24. Cyr MC, Martens AC, Berbiche D, Perreault S, Blais L. Continuity of care in the ambulatory treatment of adolescents with asthma. J Adolesc Health 2006;39: 926.e11-926.e17.

25. Hong JS, Kang HC, Kim J. Continuity of care for elderly patients with diabetes mellitus, hypertension, asthma, and chronic obstructive pulmonary disease in Korea. J Korean Med Sci 2010;25:1259-71.

26. Gill JM, Mainous AG 3rd, Nsereko M. The effect of continuity of care on emergency department use. Arch Fam Med 2000;9:333-8.

27. Cheng TM. Taiwan's new national health insurance program: genesis and experience so far. Health Aff (Millwood) 2003;22:61-76.

28. Wu CY, Chen YJ, Ho HJ, et al. Association between nucleoside analogues and risk of hepatitis B virusrelated hepatocellular carcinoma recurrence following liver resection. JAMA 2012;308:1906-13.

29. Centers for Medicare and Medicaid Services (CMS).
CCW chronic conditions: combined Medicare and Medicaid data. Available from: https://ccwdata.org/ cs/groups/public/documents/document/chron_ cond_algo_req_proc.pdf. Accessed May 20, 2016.

30. Christakis DA, Wright JA, Koepsell TD, Emerson $\mathrm{S}$, Connell FA. Is greater continuity of care associated with less emergency department utilization? Pediatrics 1999;103(4 Pt 1):738-42.

31. Christakis DA, Mell L, Koepsell TD, Zimmerman FJ, Connell FA. Association of lower continuity of care with greater risk of emergency department use and hospitalization in children. Pediatrics 2001;107: 524-9.

32. Guide to prevention quality indicators: hospital admission for ambulatory care sensitive conditions. Rockville, MD: Agency for Healthcare Research and Quality, Department of Health and Human Services; 2001.

33. Bice TW, Boxerman SB. A quantitative measure of continuity of care. Med Care 1977;15:347-9.

34. Smedby Ö, Eklund G, Eriksson EA, Smedby B. Measures of continuity of care: a register-based correlation study. Med Care 1986;511-8.

35. Chen CC, Cheng SH. Does pay-for-performance benefit patients with multiple chronic conditions? Evidence from a universal coverage health care system. Health Policy Plan 2016;31:83-90.

36. Cheng SH, Hou YF, Chen CC. Does continuity of care matter in a health care system that lacks referral arrangements? Health Policy Plan 2011;26:157-62.

37. Hsu CH, Chou YJ, Pu C. The effect of continuity of care on emergency room use for diabetic patients varies by disease severity. J Epidemiol 2016;5:413-9.

38. Moore WC, Bleecker ER, Curran-Everett D, et al. Characterization of the severe asthma phenotype by the national heart, lung, and blood institute's severe asthma research program. J Allergy Clin Immunol 2007;119:405-13.

39. Ma YC, Lin CC, Yang SY, Chen HJ, Li TC, Lin JG. Time trend analysis of the prevalence and incidence of diagnosed asthma and traditional chinese medicine use among adults in Taiwan from 2000 to 2011: a population-based study. PLoS One 2015;10: e0140318.

40. Campbell SM, Reeves D, Kontopantelis E, Sibbald B, Roland M. Effects of pay for performance on the quality of primary care in England. N Engl J Med 2009;361:368-78.

41. Huang ST, Wu SC, Hung YN, Lin IP. Effects of continuity of care on emergency department utilization in children with asthma. Am J Manag Care 2016;22:e31-7.

42. Luskin AT, James T 3rd, DeVita NG. Optimizing outcomes in asthma through a pay-for-quality-performance program. Am Health Drug Benefits 2009; 2(Suppl 9):S229-42.

43. Quan H, Sundararajan V, Halfon P, et al. Coding algorithms for defining comorbidities in ICD-9-CM 
and ICD-10 administrative data. Med Care 2005; 1130-9.

44. Schoenfeld D. Partial residuals for the proportional hazards regression model. Biometrika 1982; 69:239-41.

45. Brand PL. Inhaled corticosteroids reduce growth. Or do they? Eur Respir J 2001;17:287-94.

46. Katz DA, McCoy KD, Vaughan-Sarrazin MS. Does greater continuity of veterans administration primary care reduce emergency department visits and hospitalization in older veterans? J Am Geriatr Soc 2015;63:2510-18.

47. Asch DA, Troxel AB, Stewart WF, et al. Effect of financial incentives to physicians, patients, or both on lipid levels: a randomized clinical trial. JAMA 2015;314:1926-35.

48. Drazen JM, Postma DS, Rabe KF. The asthmaCOPD overlap syndrome. N Engl J Med 2015;373: 1241-9.

49. Menec VH, Sirski M, Attawar D, Katz A. Does continuity of care with a family physician reduce hospitalizations among older adults? J Health Serv Res Policy 2006;11:196-201.

50. Cho KH, Kim YS, Nam CM, et al. The association between continuity of care and all-cause mortality in patients with newly diagnosed obstructive pulmonary disease: a population-based retrospective cohort study, 2005-2012. PLoS One 2015;10:e0141465.

51. Crapo RO. Pulmonary-function testing. N Engl J Med 1994;331:25-30.

52. Hong JS, Kang HC. Continuity of ambulatory care and health outcomes in adult patients with type 2 diabetes in Korea. Health Policy 2013;109: $158-65$.

53. van Walraven C, Oake N, Jennings A, Forster AJ. The association between continuity of care and outcomes: a systematic and critical review. J Eval Clin Pract 2010;16:947-56.

54. Christakis DA, Kazak AE, Wright JA, Zimmerman FJ, Bassett AL, Connell FA. What factors are associated with achieving high continuity of care? Fam Med 2004;36:55-60.

55. Okumura MJ, Hersh AO, Hilton JF, Lotstein DS. Change in health status and access to care in young adults with special health care needs: results from the 2007 National Survey of Adult Transition and Health. J Adolesc Health Care 2013;52:413-8.

56. Chen CC, Cheng SH. Better continuity of care reduces costs for diabetic patients. Am J Manag Care 2011;17:420-7. 


\begin{tabular}{|c|c|c|c|c|}
\hline \multirow[b]{2}{*}{ Variables } & \multicolumn{2}{|c|}{ Crude Model } & \multicolumn{2}{|c|}{ Adjusted Model } \\
\hline & HR & $95 \%$ CI & $\mathrm{HR}$ & $95 \% \mathrm{CI}$ \\
\hline \multicolumn{5}{|l|}{ COCI } \\
\hline 1 (Reference) & 1.00 & & 1.00 & \\
\hline $0.47-0.99$ & 2.03 & $1.34-3.09$ & 1.21 & $0.76-1.91$ \\
\hline$<0.47$ & 2.73 & $1.99-3.74$ & 2.11 & $1.52-2.92$ \\
\hline \multicolumn{5}{|l|}{ Patient characteristics at baseline } \\
\hline \multicolumn{5}{|l|}{ Sex } \\
\hline Female (4eference) & 1.00 & & 1.00 & \\
\hline Male & 1.49 & $1.11-1.99$ & 1.27 & $0.94-1.72$ \\
\hline Age (years) & 1.01 & $0.99-1.03$ & 1.00 & $0.97-1.02$ \\
\hline \multicolumn{5}{|l|}{ Insurance premium (US\$) } \\
\hline$<667$ (Reference) & 1.00 & & 1.00 & \\
\hline $667-1333$ & 0.80 & $0.57-1.11$ & 0.92 & $0.66-1.28$ \\
\hline$\geq 1333$ & 0.65 & $0.42-1.02$ & 0.85 & $0.54-1.34$ \\
\hline \multicolumn{5}{|l|}{ Asthma $\mathrm{P} 4 \mathrm{P}$ program } \\
\hline Not enrolled (reference) & 1.00 & & 1.00 & \\
\hline Enrolled & 1.08 & $0.57-2.04$ & 0.83 & $0.43-1.60$ \\
\hline \multicolumn{5}{|l|}{ Medical conditions } \\
\hline \multicolumn{5}{|l|}{ In a previous year } \\
\hline \multicolumn{5}{|l|}{ CCI } \\
\hline 0 (Reference) & 1.00 & & 1.00 & \\
\hline $1-2$ & 1.21 & $0.65-2.26$ & 0.84 & $0.41-1.73$ \\
\hline$\geq 3$ & 2.28 & $1.69-3.06$ & 1.39 & $0.86-2.24$ \\
\hline \multicolumn{5}{|l|}{ COPD } \\
\hline No (reference) & 1.00 & & 1.00 & \\
\hline Yes & 4.81 & $3.39-6.82$ & 2.91 & $1.99-4.25$ \\
\hline \multicolumn{5}{|l|}{ In the COC period } \\
\hline \multicolumn{5}{|l|}{ Ambulatory visits, $\mathrm{n}$} \\
\hline 4-12 (Reference) & 1.00 & & 1.00 & \\
\hline $13-24$ & 2.55 & $1.72-3.78$ & 2.12 & $1.42-3.19$ \\
\hline$\geq 25$ & 0.70 & $0.50-0.96$ & 1.12 & $0.69-1.84$ \\
\hline \multicolumn{5}{|l|}{ Hospitalization } \\
\hline No (reference) & 1.00 & & 1.00 & \\
\hline Yes & 5.00 & $2.95-8.48$ & 1.36 & $0.76-2.41$ \\
\hline \multicolumn{5}{|l|}{ ED visits } \\
\hline No (reference) & 1.00 & & 1.00 & \\
\hline Yes & 10.42 & $7.47-14.54$ & 6.09 & $4.19-8.85$ \\
\hline
\end{tabular}

CCI, Charlson Comorbidity Index; CI, confidence interval; COCI, continuity of care index; COPD, chronic obstructive pulmonary disease; ED, emergency department; HR, hazard ratio; P4P, pay for performance. 